\title{
Investigation of the ice surface albedo in the Tibetan Plateau lakes based on the field observation and MODIS products
}

\author{
ZHAOGUO LI, ${ }^{1}$ YINHUAN AO, ${ }^{1}$ SHIHUA LYU, ${ }^{2,3}$ JIAHE LANG, ${ }^{1,4}{ }^{1}$ LIJUAN WEN, ${ }^{1}$ \\ VICTOR STEPANENKO, ${ }^{5}$ XIANHONG MENG, ${ }^{1}{ }^{\text {LIN ZHAO }}{ }^{1}$ \\ ${ }^{1}$ Key Laboratory of Land Surface Process and Climate Change in Cold and Arid Regions, Northwest Institute of Eco- \\ Environment and Resources, Chinese Academy of Sciences, Lanzhou 730000, China \\ ${ }^{2}$ Plateau Atmosphere and Environment Key Laboratory of Sichuan Province, School of Atmospheric Sciences, Chengdu \\ University of Information Technology, Chengdu 610225, China \\ ${ }^{3}$ Collaborative Innovation Center on Forecast and Evaluation of Meteorological Disasters, Nanjing University of Information \\ Science \& Technology, Nanjing 210044, China \\ ${ }^{4}$ University of Chinese Academy of Sciences, Beijing 100049, China \\ ${ }^{5}$ Lomonosov Moscow State University, GSP-1, 119991, Leninskie Gory, 1, bld.4, RCC MSU, Moscow, Russia \\ Correspondence: Shihua Lyu <slu@cuit.edu.cn>; Zhaoguo Li <zgli@lzb.ac.cn>
}

\begin{abstract}
The Tibetan Plateau (TP) lakes are sensitive to climate change due to ice-albedo feedback, but almost no study has paid attention to the ice albedo of TP lakes and its potential impacts. Here we present a recent field experiment for observing the lake ice albedo in the TP, and evaluate the applicability of the Moderate Resolution Imaging Spectroradiometer (MODIS) products as well as ice-albedo parameterizations. Most of the observed lake ice albedos on TP are $<0.12$, and the clear blue ice albedo is only $\mathbf{0 . 0 7 5}$, much lower than reported in the previous studies. Even that of ice covered with snow patches is only 0.212. MOD10A1 albedo product has the best agreement with observations, followed by those of MYD10A1. MCD43A3 product is consistently higher than the observations. Due to an error of snow flag and inconsistent time windows in MCD43A2 and MCD43A3, at certain times, the albedo of the ice without snow is even higher than that covered with snow. When the solar zenith angle is not considered, there is no significant correlation between the albedo and the ice surface temperature. None of the existing ice-albedo parameterizations can reproduce well the observed relationship of the albedo and surface temperature.
\end{abstract}

KEYWORDS: ice/atmosphere interactions, lake ice, remote sensing, snow/ice surface processes

\section{INTRODUCTION}

Surface albedo, which controls the surface shortwave radiation balance, is a fundamental parameter in climate models (Guo and others, 2013). An investigation found that the rapid increase in water temperature in Superior Lake is caused by a positive ice-albedo feedback (Austin and Colman, 2007). Ice cover can increase the lake surface albedo and thus decrease the absorbed solar radiation (Ingram and others, 1989). Conversely, the melting of ice is mainly determined by the solar radiation absorbed by the lake (Efremova and Pal'shin, 2011). Melting in advance of lake ice can lead to an earlier establishment of the summer thermocline, which accelerates the warming of the upper water body (Austin and Colman, 2007; Hampton and others, 2008; O'Reilly and others, 2015).

Previous studies have shown that lake ice albedos range from 0.10 to 0.60 (Bolsenga, 1969; Heron and Woo, 1994; Gardner and Sharp, 2010; Semmler and others, 2012; Svacina and others, 2014). However, low lake ice albedos $(<0.2)$ have been reported by only a few studies (Bolsenga, 1969; Pärn and others, 2011). Lake ice albedo is associated with many factors, such as the solar zenith angle, ice type (Bolsenga, 1977, 1983), bubble and impurity contents (Gardner and Sharp, 2010), ice thickness (Mullen and Warren, 1988) and the cloud cover (Warren, 1982). According to Pirazzini (2009), there are currently three main types of lake ice-albedo parameterization schemes.
The simplest type uses a few specified constant values, such as LAKE 2.0 model (Stepanenko and others, 2016). Another type depends on the surface temperature, such as Flake model (Mironov and others, 2010). A more complex type also considers snowfall, snow/ice thickness and other factors, such as the Canadian lake ice model (Svacina and others, 2014). Most schemes are developed based on the early high-latitude sea or lake observations or are even derived from sea ice models. Early in our investigation, based on MODIS products, we found that these schemes severely overestimate the ice albedos of the Tibetan Plateau (TP) lakes. In high-latitude lakes, the ice surfaces are often covered with snow due to the humid climate and weak solar radiation. The effect of albedo error is largely diluted by snow cover. However, there is often little snow on the lake ice in the TP due to strong solar radiation and a dry climate. Inaccurate ice albedo can lead to larger biases in the simulation of the lake temperature (Hall and $\mathrm{Qu}$, 2006; Svacina and others, 2014).

The TP lakes, with a total area of $4.7 \times 10^{4} \mathrm{~km}^{2}$ (Zhang and others, 2014), are sensitive to climate change and have an important influence on the water resources of Asia (Zhang and others, 2017). Recently, observation studies of the TP lakes have increased significantly (Biermann and others, 2014; Li and others, 2015; Huang and others, 2016; Kirillin and others, 2017; Wang and others, 2017). However, little attention has been paid to ice-albedo 
observation, due to the harsh environment in winter. In February 2017, a field experiment aiming to investigate the radiation budget of lake ice surface, including the in situ and mobile observations, was carried out in Ngoring Lake in the eastern TP. Mobile observation can enlarge the spatial representation of the observation, and make it easier to compare with the remote-sensing product. Compared with a previous similar study (Hudson and others, 2012), we adopted a mobile platform of hollow steel frame and reduced its interference with the albedo observation. In this study, we introduce this experiment and data in Section 2, and evaluate the applicability of MODIS albedo products as well as the ice-albedo parameterization schemes in the TP lakes using experimental data (Section 3). In Section 4, the effectiveness of the albedo observations and the influence of the ice albedo on lake simulation are discussed. Finally, in Section 5, the conclusions are presented.

\section{STUDY AREA, FIELD EXPERIMENT AND DATA}

\subsection{Study area and field experiment}

Ngoring Lake (4274 m a.m.s.l.) is located in the Yellow River source region of the eastern TP, with a mean depth of $17 \mathrm{~m}$ and a surface area of $610 \mathrm{~km}^{2}$, which is the highest large fresh water lake in China. The Ngoring Lake basin is characterized by a cold and semi-arid continental climate. From early December to early April, the lake is usually completely ice-covered, and the average precipitation is only $28.16 \mathrm{~mm}$ (year 1954-2014). Our data show that the observed thickest ice is $\sim 0.7 \mathrm{~m}$ in 2013 and 2016 and typically appears in late February.

From 10 February to 18 February 2017, a field experiment was carried out over western Ngoring Lake (Fig. 1). The in situ observation station (IOS) was placed on the ice surface $240 \mathrm{~m}$ from the lakeshore $\left(34.905^{\circ} \mathrm{N}, 97.571^{\circ} \mathrm{E}\right)$, where the ice thickness was $0.6 \mathrm{~m}$. Turbulent fluxes, radiation components and standard atmospheric variables were measured at IOS. A mobile observation platform (MOP) was used to measure the radiation balance of the ice surface over larger region (Fig. 2). Both the IOS and MOP used the Kipp \& Zonen CNR4 four-component net radiometer to measure the broadband downward and upward shortwave and longwave radiations at heights of $1.20 \mathrm{~m}$ (IOS) and $1.60 \mathrm{~m}$ (MOP), respectively. For the IOS, the CNR4 measured once per minute and output a group of average data every 30 min. For the MOP, the CNR4 measured once per $10 \mathrm{~s}$ and output a group of average data every $60 \mathrm{~s}$. The MOP had a built-in GPS sensor, which can record the instrument position in real time. In addition, a four-rotor unmanned aerial vehicle (UAV) was used to take aerial photos (Fig. 3d) with a maximum flight height of $500 \mathrm{~m}$.

\subsection{DATA}

\subsubsection{Observation data}

The ice surface temperature can be estimated from the downward and upward longwave radiation measurements by

$$
T_{\mathrm{s}}=\left[\frac{R I_{\text {up }}-(1-\varepsilon) R I_{\mathrm{dw}}}{\varepsilon \sigma}\right]^{0.25} .
$$

Here, $\sigma\left(=5.67 \times 10^{-8} \mathrm{~W} \mathrm{~m}^{-2} \mathrm{~K}^{-4}\right)$ is the Stefan-Boltzmann constant; $R I_{\mathrm{dw}}$ and $R I_{\text {up }}$ are the downward and upward longwave radiations, and $T_{\mathrm{s}}$ is the ice surface temperature. Following Wilber and others (1999), a surface emissivity $\varepsilon$ of 0.99 is employed in Eqn (1). There is some uncertainty
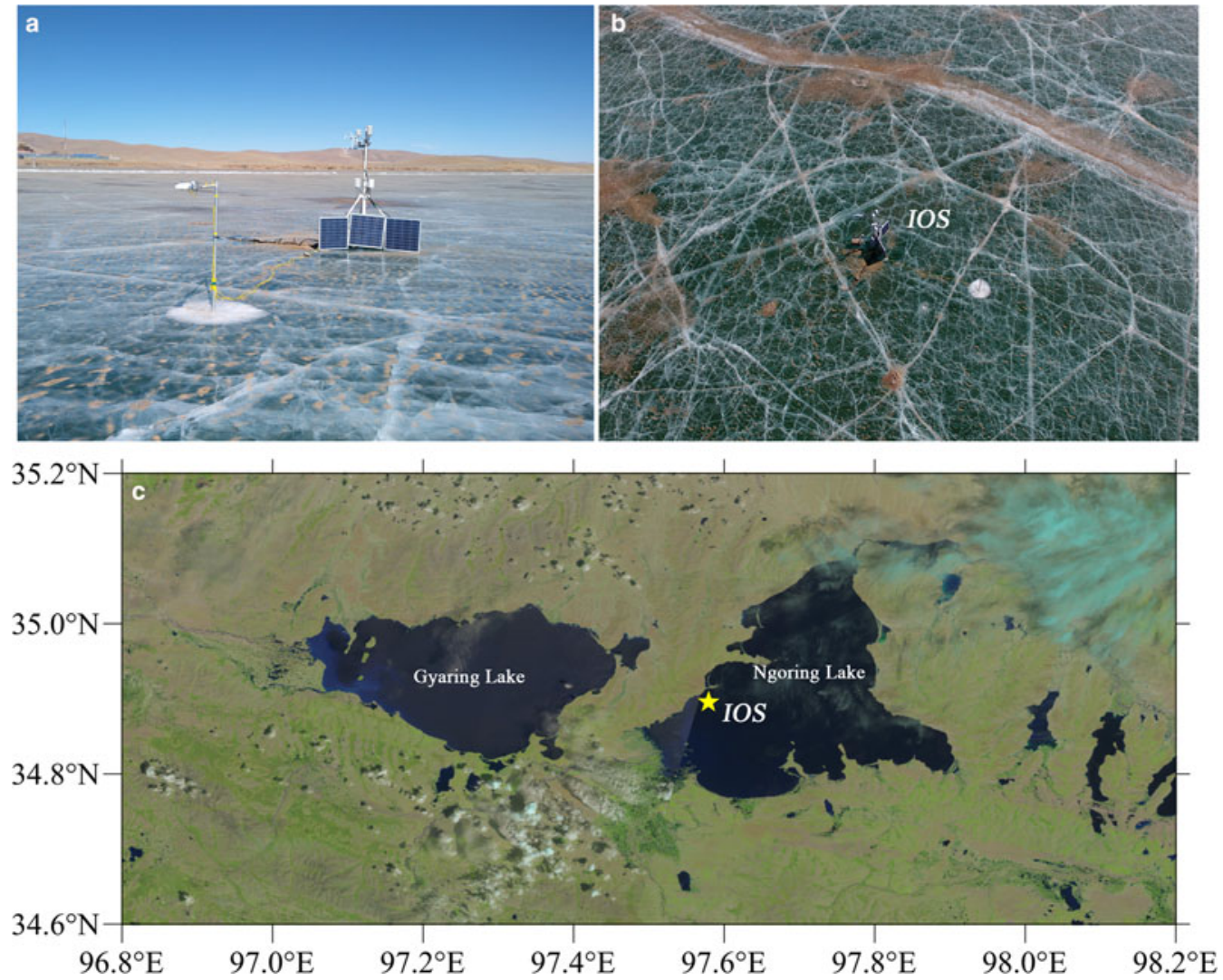

Fig. 1. The IOS on the ice surface (a), the aerial photo of the IOS using the UAV (b) and its location (the yellow five-pointed star) (c). 

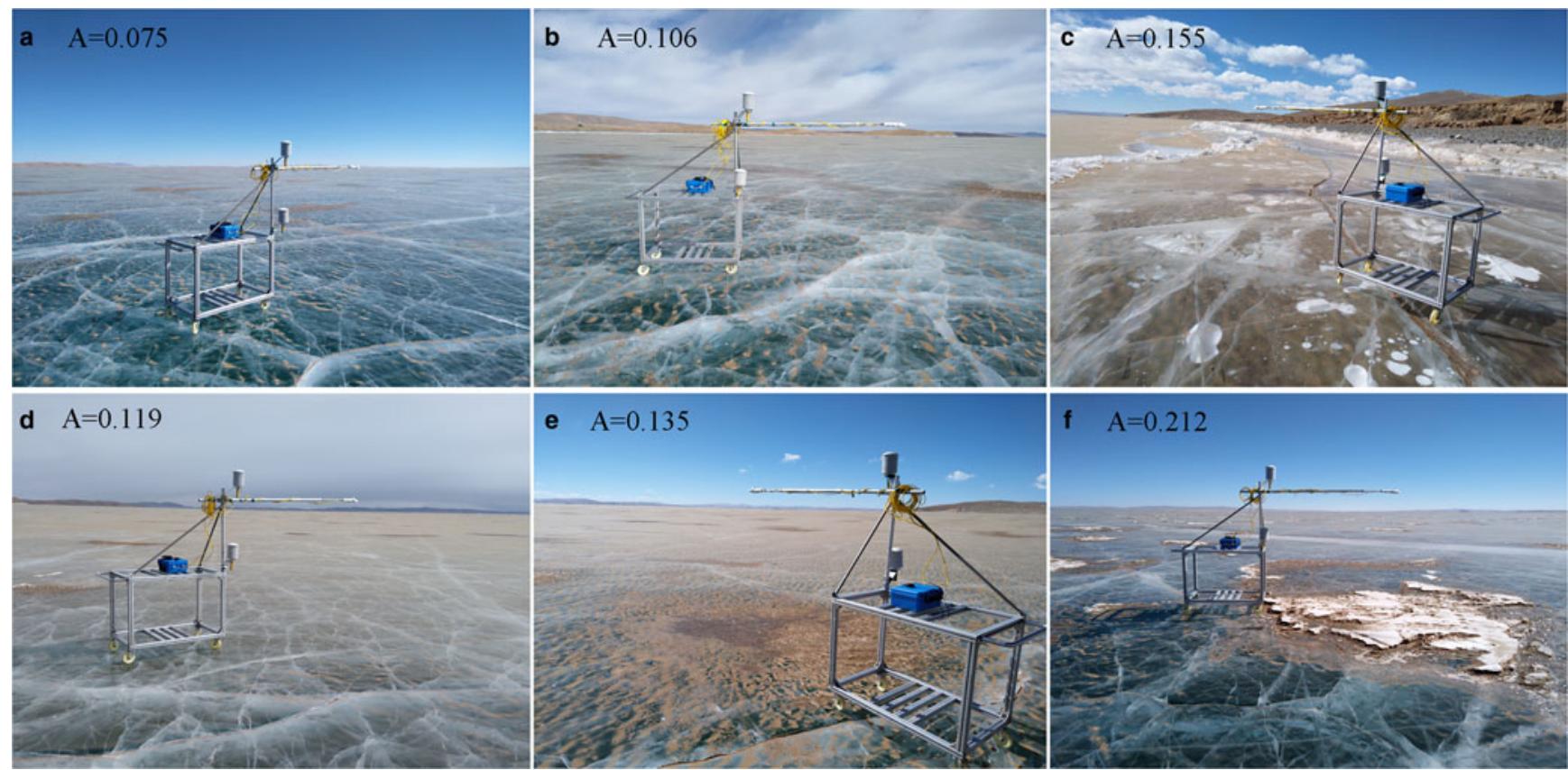

Fig. 2. Photos and albedos of different types of lake ice from the MOP.

in the surface emissivity of ice. However, a sensitivity test in this study indicates that its small fluctuations (from 0.97 to 0.99) have little effect on the surface temperature (the maximal difference is only $0.64{ }^{\circ} \mathrm{C}$ ). $T_{\mathrm{s}}$ is employed in the parameterization scheme to obtain the model-derived ice surface albedo. During the observation period, clear ice was dominant, but sporadic snow cover could also be found (Fig. 2). The in situ observation began on 10
February and ended on 18 February. For the mobile observations, the wind speed increased too much in the afternoons and threatened the safety of observers, so measurements were carried in the late mornings (local time 10:00-12:00) of $11,12,14,15,16$ and 17 February. During this period, the solar zenith angle is $<60^{\circ}$, and the influence of its variation on albedo can be approximately ignored. In addition, the observation data for water temperature in Ngoring Lake
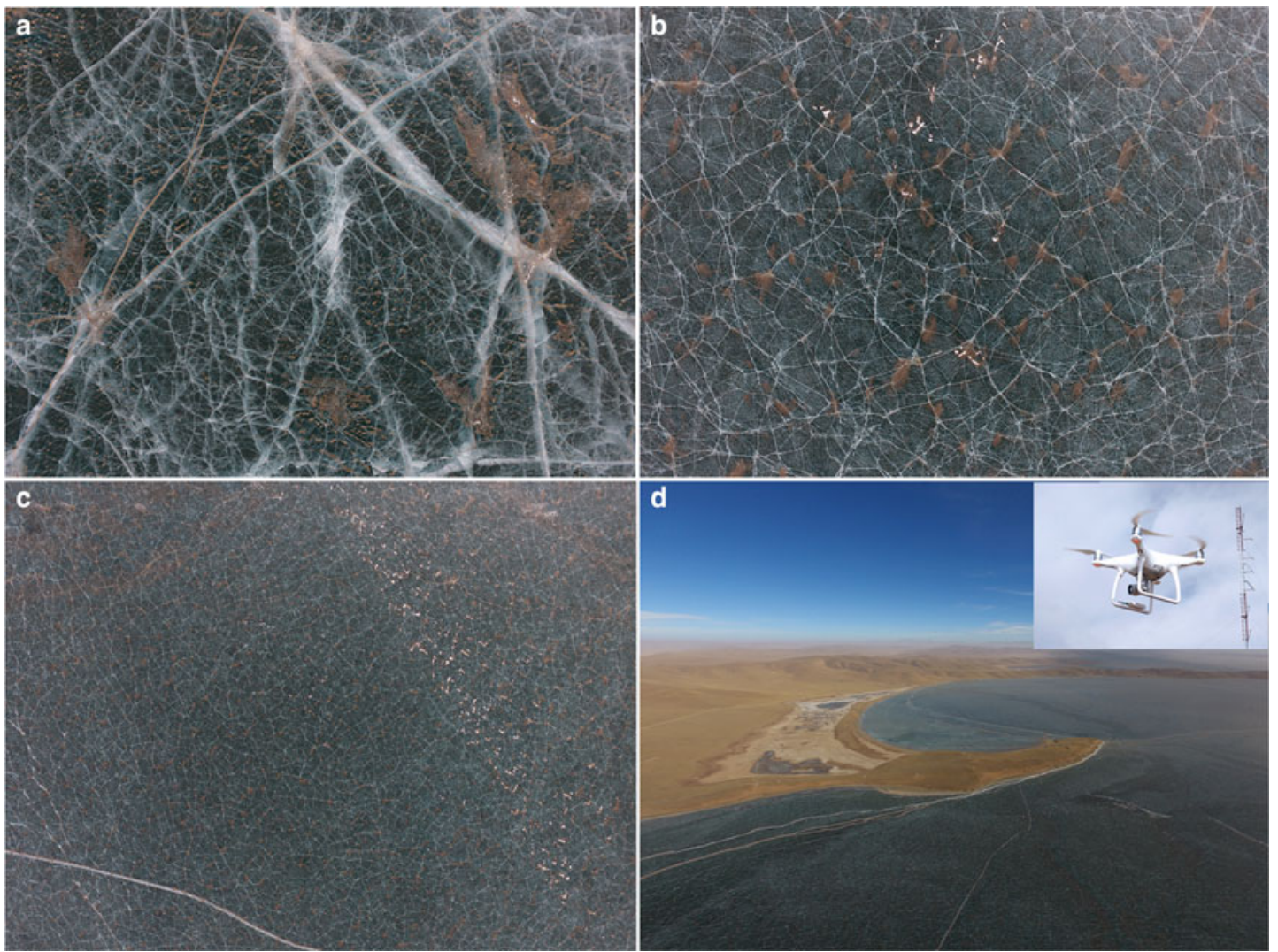

Fig. 3. The aerial photos of the lake ice at $10 \mathrm{~m}(\mathrm{a}), 100 \mathrm{~m}(\mathrm{~b})$ and $500 \mathrm{~m}(\mathrm{c}, \mathrm{d})$ heights using the UAV. The UAV took the first three photos $(\mathrm{a}, \mathrm{b}$, c) looking straight down from the belly of the UAV over the same place, and the fourth photo (d) was taken in an approximate horizontal direction. A photo of the UAV is added to the top right-hand corner of Figure $3 \mathrm{~d}$. 
from 22 September 2015 to 21 September 2016 are also used in this study to evaluate simulation results from LAKE 2.0 model (Section 2.4).

\subsubsection{MODIS products}

The MODIS albedo products used in this study are the MOD10A1/MYD10A1 V006 daily albedos, the MCD43A3 $16 \mathrm{~d}$ albedo and the quality assurance product MCD43A2, which determines whether the albedo is recorded for a snow-covered pixel. The MOD10A1(Terra)/MYD10A1 (Aqua) products include the snow/ice albedo and the fraction of snow cover at a spatial resolution of $500 \mathrm{~m}$ (Hall and Riggs, 2007). The MCD43A3 product combines the albedo retrievals from the Terra and Aqua satellites at a $500 \mathrm{~m}$ spatial resolution. The latest version (V006) of MCD43A3 is updated every day, and uses the current day's snow status instead of the majority snow/no-snow status from the $16 \mathrm{~d}$ period in the V005 version (https://lpdaac.usgs.gov/dataset_ discovery/modis/modis_products_table/mcd43a3_v006). The clear sky is dominant during the observation period. The MOD10A1/MYD10A1 products are retrieved exclusively under clear-sky conditions. For the MCD43A3, the black sky albedo is used for this study because it represents the albedo under clear-sky conditions. In this study, the MOD11A1/MYD11A1 surface temperature products are also used to evaluate the simulation results.

\subsection{Lake ice-albedo parameterizations}

Many parameterization schemes of the lake ice albedo have been developed and have varying degrees of complexity. In the Weather Research and Forecasting (WRF) Model, the lake ice albedo of a completely frozen lake is 0.6. In the 1-D lake model LAKE 2.0 (Stepanenko and others, 2016), the ice albedo is also 0.6. Temperature-dependent albedo schemes usually have a minimum and maximum albedo values, respectively, corresponding to the melting conditions and to the surface temperatures below a certain threshold. These schemes mainly originate from the observations of sea ice or glaciers (Ross and Walsh, 1987; Brock and others, 2000; Pirazzini and others, 2006). The ice surface albedo $\left(a_{\mathrm{i}}\right)$ scheme in FLake model is derived from a sea ice model (Mironov and Ritter, 2004):

$$
a_{i}=a_{\max }-\left(a_{\max }-a_{\min }\right)\left[\exp \left(-\frac{95.6\left(T_{\mathrm{f}}-T_{\mathrm{s}}\right)}{T_{\mathrm{f}}}\right)\right],
$$

where $a_{\max }$ is set to 0.60 , referring to the albedo of white ice or snow ice, and the blue ice albedo $\left(a_{\min }\right)$ is equal to 0.10 . As $T_{\mathrm{s}}$ approaches the freezing point $\left(T_{\mathrm{f}}\right)$, the albedo moves toward 0.10 based on Mironov and others (2010). In the WRF-FLake model (Mallard and others, 2014), the white ice or snow ice $\left(a_{\max }\right)$ is set to 0.80 ; other variables remain unchanged.

In some models, a separate dependency of albedo on surface temperature is prescribed for visible and near-infrared wavelengths (Roesch and others, 2002). In the Community Land Model (CLM) version 4.5 (Oleson and others, 2013), the lake ice albedo without resolved snow layers is similar to that of FLake:

$$
a_{i}=a_{0}-\left(a_{0}-0.10\right)\left[\exp \left(-\frac{95\left(T_{\mathrm{f}}-T_{\mathrm{s}}\right)}{T_{\mathrm{f}}}\right)\right]
$$

The albedo at cold temperatures $a_{0}$ is 0.60 for visible and 0.40 for near-infrared radiation. For frozen lakes with resolved snow layers, the reflectance of the ice surface is fixed at $a_{0}$. In the General Lake Model (GLM) 2.0 (Hipsey and others, 2014), the ice surface albedo is a function of surface temperature and ice thickness (Svacina and others, 2014):

$$
a_{\mathrm{i}}=\left\{\begin{array}{cc}
c_{1} h_{\mathrm{i}}^{0.28}+0.08 & T_{\mathrm{s}}<T_{\mathrm{f}} \\
\min \left(a_{\mathrm{mi}}, c_{2} h_{\mathrm{i}}^{2}+a_{\mathrm{w}}\right) & T_{\mathrm{s}}=T_{\mathrm{f}}
\end{array},\right.
$$

where $a_{w}$ is the albedo of open water (0.05), $a_{m i}$ is the albedo of melting ice (0.55), $h_{\mathrm{i}}$ is the ice thickness $(\mathrm{m}), c_{1}$ is a constant equal to $0.44 \mathrm{~m}^{-0.28}$ and $c_{2}$ is a constant equal to $0.075 \mathrm{~m}^{-2}$.

\subsection{LAKE 2.0 model}

LAKE 2.0 is a 1-D lake model for solving horizontally averaged equations for heat, gases and momentum transport (Stepanenko and others, 2016). In this model, the near-infrared solar radiation is consumed completely at the water surface, whereas the visible solar radiation is partially reflected according to water albedo, and its remainder attenuates with depth according to an extinction coefficient specific for the lake. In this study, the extinction coefficient for water is set to be 0.15 referencing the observation result from Nam Co Lake in the TP (Nima and Zhuo, 2012). LAKE 2.0 model also includes multilayer snow and ice modules (Stepanenko and Lykossov, 2005; Stepanenko and others, 2011). In LAKE 2.0, several different turbulent mixing parameterizations can be selected. In this study, we use a standard $\mathrm{k}-\varepsilon$ (K-epsilon) parameterization scheme to calculate eddy diffusivity. The inflow and outflow of the lake are disregarded, because of their small effect on the water balance of Ngoring Lake.

\section{RESULTS}

\subsection{Daily cycle of the albedo}

The peaks of the downward shortwave radiation exceed 800 $\mathrm{W} \mathrm{m} \mathrm{m}^{-2}$ during most days (Fig. 4a), with a maximum value of $899.13 \mathrm{~W} \mathrm{~m}^{-2}$, which is even greater than the maximum solar radiation observed in the high-latitude lakes in summer (Rouse and others, 2003). The upward shortwave radiations are all $<90 \mathrm{~W} \mathrm{~m}^{-2}$ except for that on 11 February. In contrast, the upward longwave radiation is significantly greater than the downward longwave radiation. The daily mean downward and upward shortwave radiations are 204.20 and $24.75 \mathrm{~W} \mathrm{~m}^{-2}$ from 11 February to 17 February, respectively. The downward and upward longwave radiations are 172.04 and $268.59 \mathrm{~W} \mathrm{~m}^{-2}$, respectively. The mean net radiation $\left(79.29 \mathrm{~W} \mathrm{~m}^{-2}\right)$ is obviously less than that in summer $\left(178.01 \mathrm{~W} \mathrm{~m}^{-2}\right)$, but greater than that before the lake freezes in the early winter $\left(24.11 \mathrm{~W} \mathrm{~m}^{-2}\right)(\mathrm{Li}$ and others, 2015). Generally, strong downward shortwave radiation means that a slight variation in albedo can cause a drastic change in the energy absorbed by the lake. The ice surface albedo can reach $\sim 0.30$ after sunrise and before sunset, and decreases to 0.08-0.09 around noon. This albedo is clearly lower than that reported previously (Zdorovennova and others, 2013; Svacina and others, 2014), especially when the ice is thick $(0.6 \mathrm{~m})$. Note that 

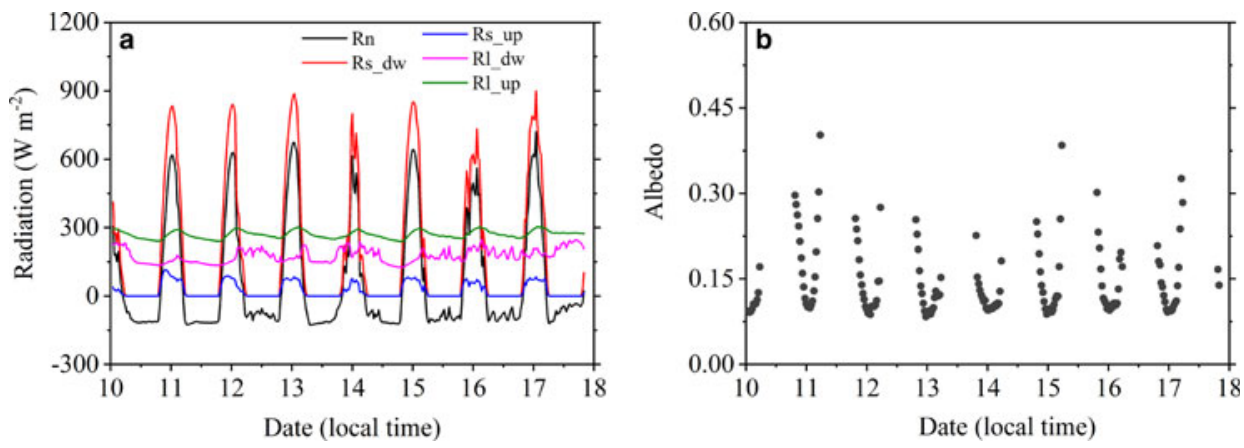

Fig. 4. Daily cycles of the radiation components (a) and the ice surface albedos (b) from the IOS in February 2017 (the dates in the horizontal axis are days of February). (Rn: net radiation; Rs_dw and RI_dw: downward shortwave and longwave radiations; Rs_up and Rl_up: upward shortwave and longwave radiations).

the ice structure (with a radius of $0.45 \mathrm{~m}$ ) below the radiation bracket at IOS is partly broken during installation, which causes some original blue ice to become white because of intruded air bubbles. The overestimation of the albedo due to this phenomenon should be slight because it is not directly beneath the CNR-4 sensor and only covers a small area.

\subsection{Mobile observation of the albedo}

Based on the GPS and radiation data, the observation paths and albedos are presented in Figure 5. The maximum observation range is $\sim 630 \mathrm{~m}$ in the meridional direction, and $960 \mathrm{~m}$ in the latitudinal direction, which is larger than a MODIS pixel. We obtain 529 groups of valid data within $6 \mathrm{~d}$.

Although the ice surface is relatively flat, its radiation budget is still affected by many processes that occur at small scales (order of 1-10 m), such as the existence of air bubbles, cracks, dust, variations of ice color, thickness and water depth. Therefore, the MOP walks randomly across the ice. On an ordinary ice surface, the MOP moves slowly at $\sim 0.5 \mathrm{~m} \mathrm{~s}^{-1}$. However, when encountering a characteristic ice surface (e.g. the blue ice, white ice, crack ice, bubble ice, the ice covered with dust or snow), the MOP will stay on the ice for 3-4 min, in order to obtain the typical albedo value of that type of ice. This kind of specific observation accounts for $\sim 15 \%$ of the total MOP data. As shown in Figure 5, the lake ice albedos are $<0.12$ for most areas. The albedos at the clear blue line (0.12-0.15) are relatively high, which may be associated with the relatively large amount of dust that covered the ice on 11 February (photo is inlaid in Fig. 5). The albedos above 0.15 usually come from the stationary observations of the ice covered with patched snow or dust. As shown in Figure 6, the albedo samples ranging from 0.08 to 0.12 account for $65.41 \%$ of the total MOP data, and 42.72 and $72.21 \%$ of the samples are $<0.10$ and 0.12 , respectively. Further, 93.38\% samples are below 0.16. For the statistic characteristics of the albedos in each interval, both the median lines and the mean values are left of the $0.08-0.10,0.10-0.12$ and $0.12-0.14$ intervals and toward the lower albedos.

Photos of six typical types of lake ice and their albedos are presented in Figure 2. The albedo of the relatively clean blue ice is only 0.075 (Fig. 2a), which is very close to the water surface albedo in Ngoring Lake (0.04-0.05) (Li and others, 2015). The cracked ice is a little white due to intruded air bubbles, and its albedo is $\sim 0.106$ (Fig. 2b). The ice near the lake shore usually contains a few small snow patches,

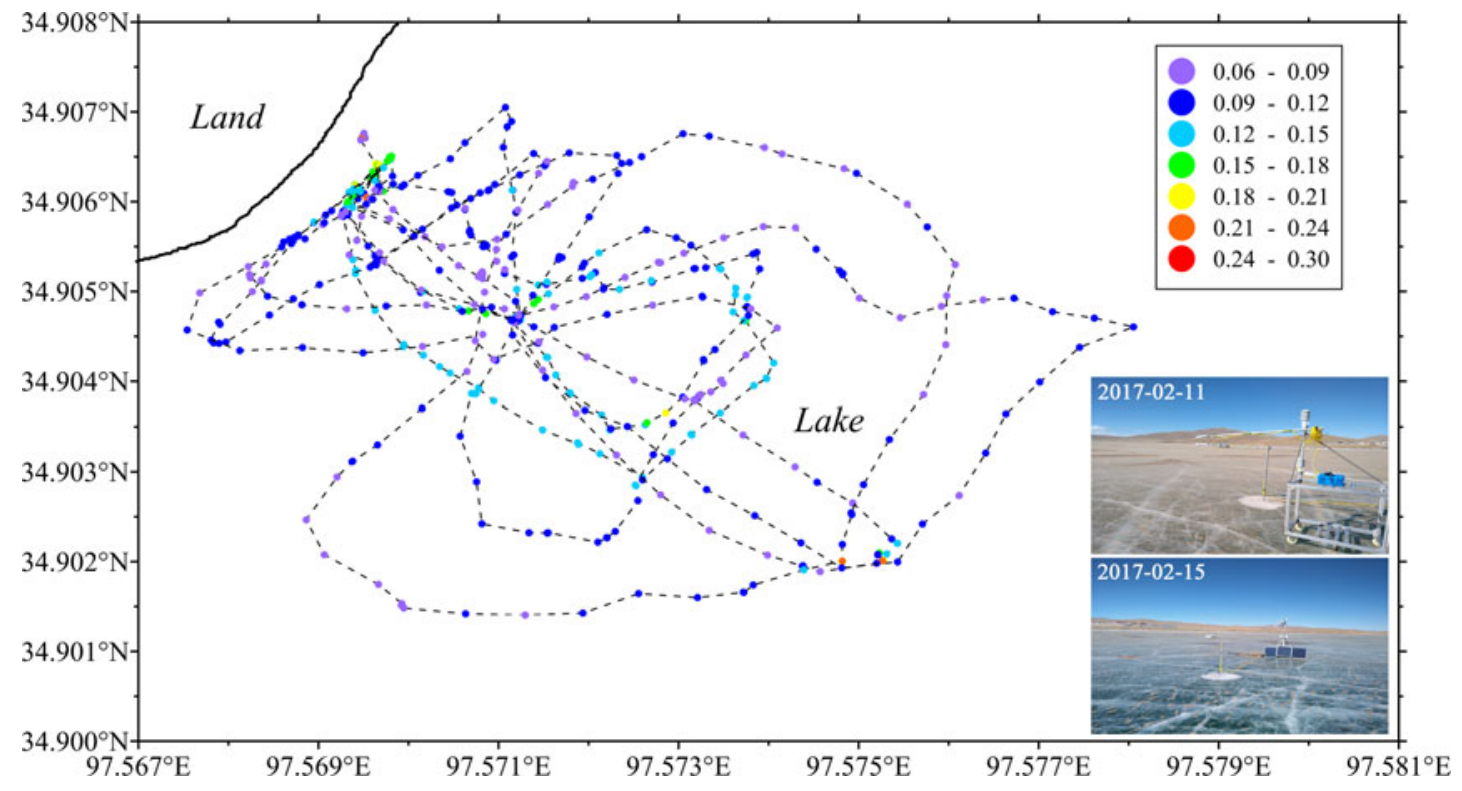

Fig. 5. Spatial distribution of the ice surface albedo using the MOP data of $6 \mathrm{~d}$ (photos of ice surface on February 11 and 15 are displayed in the lower right corner). 


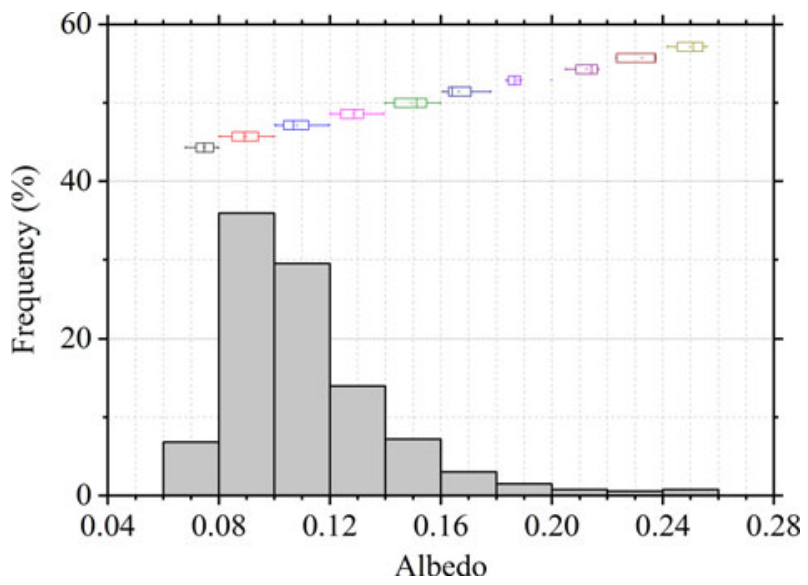

Fig. 6. Frequency distribution of the albedos from the MOP over $6 \mathrm{~d}$. The center of each box represents the median value, the edges of each box indicate the 25th and 75th percentiles, and the whiskers represent the 5th and 95th percentiles of the distributions.

and the water is shallow (the lake-bottom sediment is visible). Therefore, the albedo is obviously high (0.155) (Fig. 2c). When the ice is covered with dust and the cracks are obvious, the albedo (0.119) is higher than that of clean blue ice (Fig. 2d). Part of the ice surface is full of tiny wavy wrinkles, and sand or sediment is easily gathered. Its albedo is $\sim 0.135$ (Fig. 2e). Note that the viewing angle of the downward-looking shortwave radiation sensor is up to $150^{\circ}$, and the observation radius below the sensor can reach $5.97 \mathrm{~m}$ when the sensor height is $1.60 \mathrm{~m}$. This range is significantly greater than that of the sediment patches, although the upward shortwave radiation from the area directly below the sensor has a stronger effect than the marginal area. By the same token, the albedo of the ice surface covered with snow patches is only 0.212 (Fig. $2 \mathrm{f}$ ), which is much lower than that of snow.
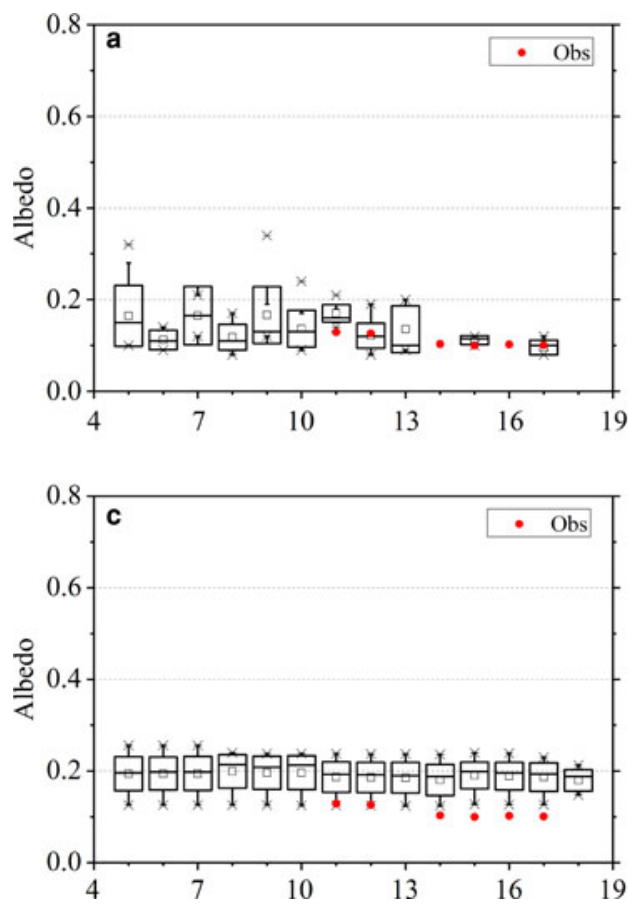

\subsection{MODIS albedo products evaluation}

A wider range of lake ice albedos can only be acquired via remote sensing. However, it is also difficult to match the locations in the MODIS data due to many missing values. Therefore, all available MODIS data over Ngoring Lake are collected. From the EOSDIS Worldview image, the snowcovered area gradually decreases from 5 February to 18 February. For MOD10A1/MYD10A (Fig. 7a, b), only the data with snow coverage ratio of $<15 \%$ per pixel are used, which is approximatively considered as a snow-free pixel. Based on the MCD43A2 product, the MCD43A3 data can be divided into snow-free (Fig. 7c) and snow-covered albedos (Fig. 7d).

Overall, the MOD10A1 products have the best agreement with the observations (Fig. 7a), followed by the MYD10A1 (Fig. 7b). The daily mean albedos measured by the MOP range from 0.10 to 0.13 , and the mean values from MOD10A1 range from 0.09 to 0.17 , with a maximum value of 0.28 and a minimum value of 0.08 (excluding outliers). Given that the MOD10A1 albedo may contain the effects of sporadic snow cover in some pixels, this result is appropriate. The albedos from MYD10A1 range from 0.10 to 0.22 , and the data are more discrete than those of MOD10A1. For the ice with snow-free flags in MCD43A2, the corresponding albedos from MCD43A3 range from 0.18 to 0.20 . The albedos during several adjacent dates are very close in the MCD43A3 because it is updated every day, but it still is a $16 \mathrm{~d}$ albedo product. The snow-covered icealbedo values range from 0.15 to 0.50 and quickly reduce with decrease in snow cover (Fig. 7d). However, the albedo of ice covered with snow is lower than that of the snowfree ice from 14 February to 18 February (Fig. 7c, d), which means that the accuracy of the snow flag in MCD43A2 is not enough. This also may happen because the snow flag uses the current day snow's status, but the albedo contains information of $16 \mathrm{~d}$. Their time windows are inconsistent.
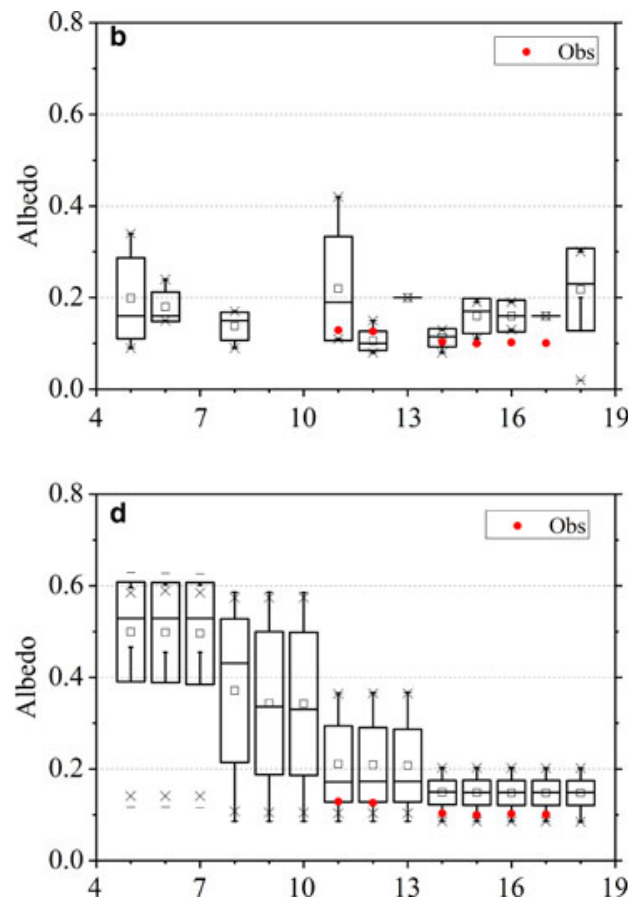

Fig. 7. The snow-free ice surface albedos (box chart) from the MOD10A1 (a), MYD10A1 (b) and MCD43A3 (c), and the ice surface albedo with snow cover from MCD43A3 (d) in February 2017 (the dates in the horizontal axis are days of February). Daily mean ice surface albedos from MOP are marked with the solid red dots. 


\subsection{Albedo parameterization schemes evaluation}

Compared with MODIS products, the differences in the albedo between the parameterizations and the observations are much larger (Fig. 8). In WRF and LAKE 2.0, the lake ice albedos are fixed at 0.6 , respectively. The ice albedos in the other schemes generally decrease with increasing surface temperatures. The albedos from CLM4.5 for the near-infrared radiation (CLM4.5/0.4) are all $<0.40$ and are even $<0.15$ when near the freezing point, which is the closest to those observed. The second closest is the FLake model. The ice albedo from GLM 2.0 is constant (0.6) when the surface temperature is lower than $-5^{\circ} \mathrm{C}$, and there is a linear relation between them when the surface temperature is $-5{ }^{\circ} \mathrm{C}$ or above. The most significant deviation exists in the WRF-FLake. The ice albedo from WRF-FLake rapidly decreases with increasing surface temperature. From all the schemes, it has the largest albedo amplitude, ranging from near 0.80 at $255.37 \mathrm{~K}$ to 0.22 at $272.64 \mathrm{~K}$. There is no significant correlation between the observed ice albedo and the surface temperature, which may be partly related to the short observation time, during which the ice thickness and albedo change very little, but the surface temperature shows an obvious daily cycle. In fact, the data employed by previous temperature-dependent albedo schemes were temporally averaged quantities as daily means or monthly means (Roesch and others, 1999), and spatially averaged satellite-derived albedo (Ross and Walsh, 1987). Therefore, rapid variations in the surface temperature were smoothed out and cannot reproduce the diurnal cycle of albedo. If the observation period were longer, the daily mean albedo and surface temperatures would be employed, and the results could be improved. However, this improvement is very slight, because the distribution of the albedo with the ice surface temperature is very scattered in the data used in parameterization development (Ross and Walsh, 1987). This means that the temperature alone is not sufficient to explain the albedo variability. We further checked the dependence of the ice albedo on the surface temperature in Ngoring Lake using MODIS products (MOD11/MYD11 land surface temperature product and MCD43A3 albedo product) from December 2012 to April 2015. The distribution of the ice albedo with the surface temperature is also very scattered and the correlation coefficient is -0.13 . Therefore, even at long time scales, the dependence relation between the albedo and the temperature is unclear. Using the IOS, data show that the ice albedo generally decreases with rising surface temperatures, but this may be due to the solar zenith angle, which is a main factor affecting the daily cycle of the ice albedo. The ice albedo is concentrated at $<0.15$ when the solar zenith angle is $<60^{\circ}$. This means that the times selected for the MOP were appropriate.

\section{DISCUSSION}

\subsection{Influence of the observation scale}

For the aforementioned differences between the MODIS and the ground observations, in addition to instrument error and the MODIS product algorithm, an inconsistency in their spatial scales is also a key factor. In recent years, some field experiments have tried to bridge the ground observation and remote sensing by establishing an observational network composed of many stations (Li and others, 2013; Yang and others, 2013; Liu and others, 2016). In this study, a mix of the IOS and MOP expands the representation of the albedo observations. However, a few differences in the view due to difference measurement heights still can be detected in aerial photographs (Fig. 3). Generally, darker surfaces have lower albedos and lighter surfaces have higher albedos (Post and others, 2000). At the $10 \mathrm{~m}$ height (Fig. 3a), the ice color has a significant variation and the white crack of the ice is quite conspicuous, which means that the albedos vary significantly in the same photo. When the height rises to $100 \mathrm{~m} \mathrm{(Fig.} \mathrm{3b),} \mathrm{the} \mathrm{ice} \mathrm{color} \mathrm{becomes} \mathrm{relatively}$ uniform. At a $500 \mathrm{~m}$ height (Fig. 3c), the ice crack becomes indistinct, but some patches of snow cover appear due to the expanded view. The land surface albedos range from 0.21 to 0.23 at noon. Compared with the land, the ice color is clearly darker (Fig. $3 \mathrm{~d}$ ). This means that the low ice albedo is reliable.

\subsection{Representation of the albedo observations}

The observations were only carried out for $8 d$ due to the tough observation conditions. Do the ice albedos change significantly at different stages? Is the low ice albedo universal across the TP lakes? From the EOSDIS Worldview images (Fig. 9), it can be seen that the colors of snow-free ice surfaces are very similar in Ngoring Lake at different stages of the frozen period, and are very close to the color of the unfrozen water. It is well known that water has a low albedo. A previous study based on the MODIS products also shows that the bare ice albedos vary very little in Ngoring Lake during the frozen period (Lang and others, 2018). In Nam Co Lake (a
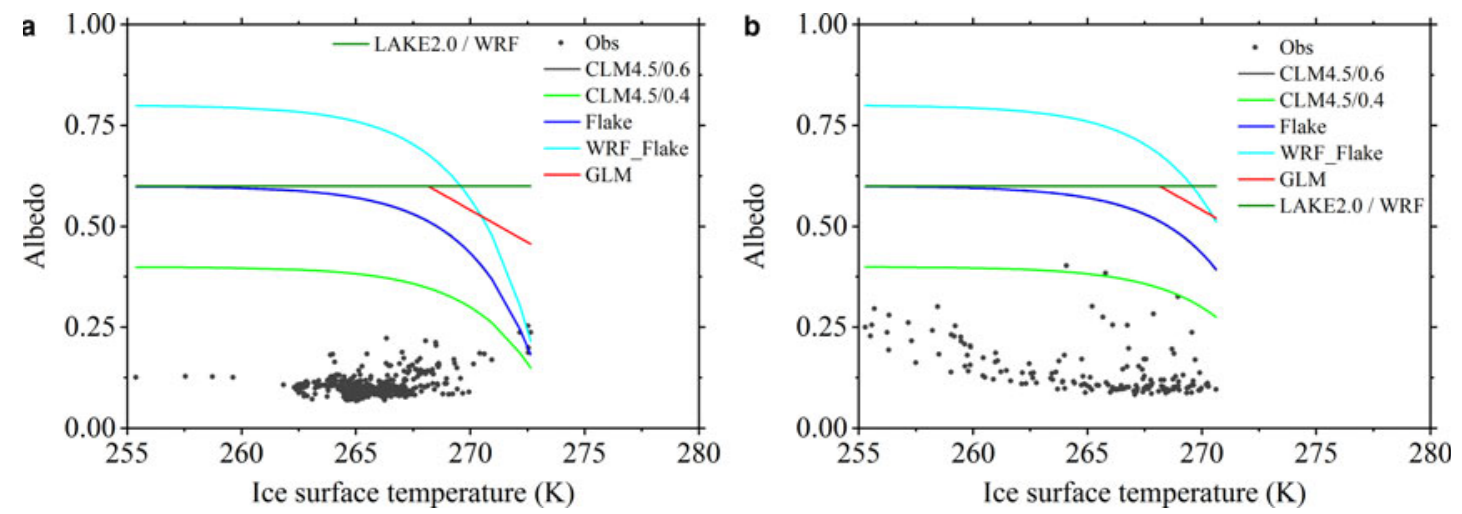

Fig. 8. The relationship between the albedo and the ice surface temperature from the different parameterization schemes using the MOP (a) and the IOS (b) data. 

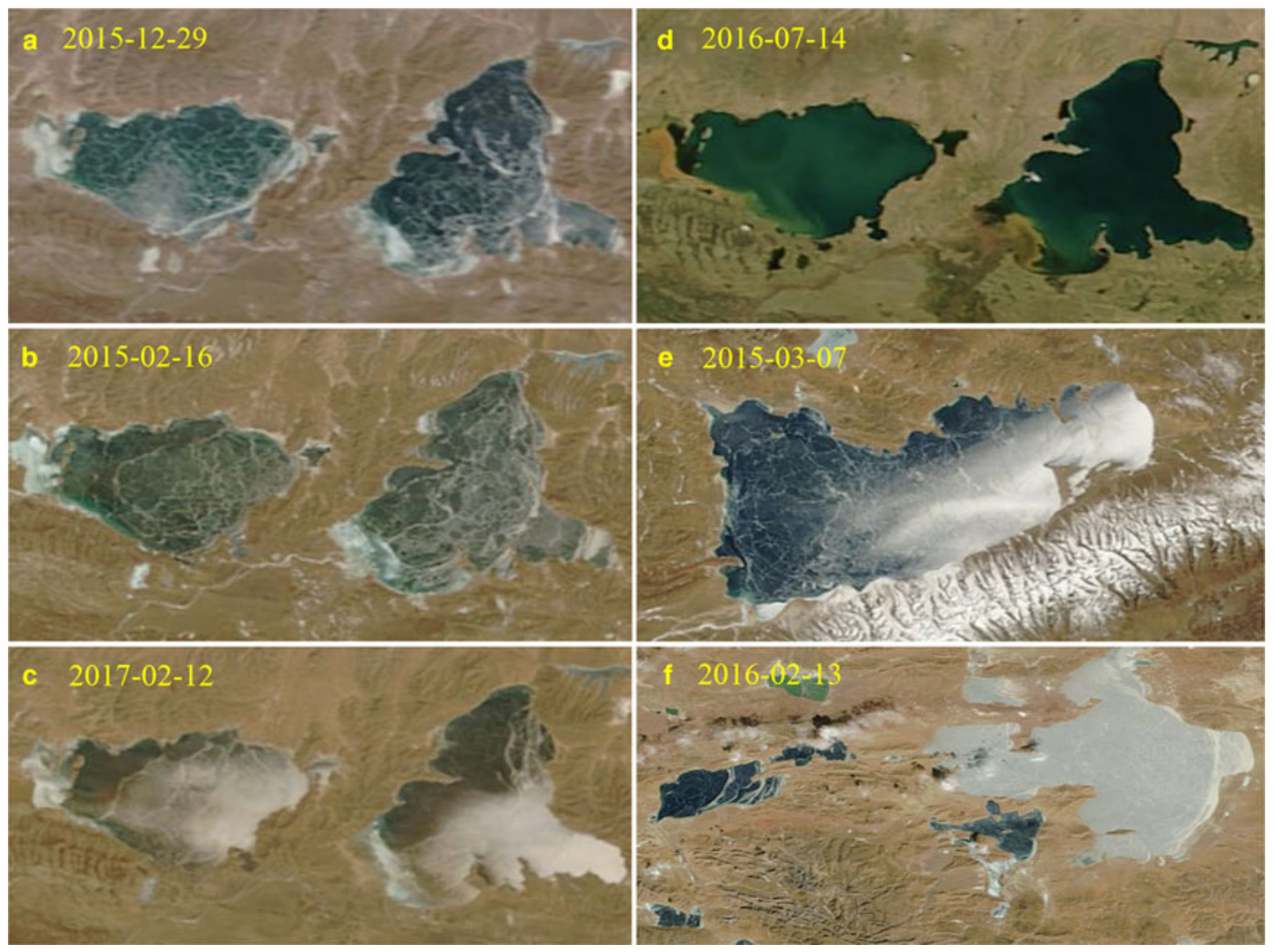

Fig. 9. The satellite images from the EOSDIS Worldview website at different times. From (a) to (d), the lakes are Gyaring Lake and Ngoring Lake, the lake in (e) is Nam Co Lake and the lakes in ( $\mathrm{f}$ ) are Siling Co Lake (the largest one) and its nearby lakes. Siling Co Lake and Nam Co Lake are the second and third largest lakes in the TP, respectively.

deep salt water lake), the snow-free ice is also very dark. Siling Co Lake looks white due to the snow cover and contrasts with the nearby lakes.

Figure 10 shows the albedo frequency distribution of the six typical TP lakes during the completely frozen period (ice cover is more than $95 \%$ of the lake area) from October 2012 to June 2015 using the MCD43A3 V005 product. Those albedos of $<0.05$ are likely due to unfrozen regions. As shown in Figure 10c, the albedos of $72.8 \%$ of the pixels in Ngoring Lake are $<0.15$ under snow-free conditions, and $94.6 \%$ of the pixels show albedos below 0.20 . For Aksai Chin Lake and Nam Co Lake, the albedos of 65.6 and $70.5 \%$ of the pixels are $<0.20$, respectively. In Whale Lake, Zhari Namco Lake and Qinghai Lake, the albedos of $67.1,70.8$ and $96.2 \%$ of the pixels are $<0.25$ under snowfree conditions, respectively. The peaks of the albedo frequency distributions in these lakes are much smaller than those resulting from the parameterization schemes. Due to the influence of the snow cover, the actual lake surface albedo is inevitably higher than that of the bare ice. However, the peaks of the albedo distribution for all the available pixels are still $<0.40$ in Aksai Chin Lake, Qinghai Lake and Zhari Namco Lake, and the proportions of albedos lower than 0.40 account for $70.0,88.9$ and $79.9 \%$ of the total pixels, respectively. Of the six lakes, the albedo peak of Nam Co Lake is the largest (0.58), and the peak is not obvious in Ngoring Lake or Whale Lake. Therefore, this phenomenon of low ice albedo in Ngoring Lake has a certain universality across the TP lakes, especially when the error of the snow-cover flag and the scale differences between the MODIS and ground-based measurements are considered.

\subsection{Influence of the ice albedo on lake simulation}

In order to study the effect of lake ice albedo, a group of numerical simulations with different ice albedos (from 0.10 to 0.80 , with an interval of 0.10 ) using LAKE 2.0 model are carried out. The forcing data (01 July 2011-31 December 2016) come from the observation in Ngoring Lake, and the main input meteorological variables include air temperature, air specific humidity, air pressure, zonal and meridional wind speeds, downward shortwave and longwave radiations and precipitation rate. As the initial state for spin-up, the lake temperature profile is given based on the observed result in Ngoring Lake in early July 2012. Then the simulation is carried out ten times with the forcing data of the first year. After this spin-up run, the lake temperature reaches the seasonally repeating equilibrium state. The final state of this spin-up run is used in turn as the initial state for the respective run (only the lake ice albedos are different).

The daily average surface temperature from all simulation experiments is presented in Figure 11. During the ice-free period, especially from July to November, the difference in the surface temperature is small between the simulated and the MODIS product, and the ice albedo has little effect on the lake surface temperature. In the larger view (Fig. 11b, c), the difference in the surface temperature due to the ice albedo is mainly manifested in the period from late November to the following June. During this stage, the lower the ice albedo, the higher the simulated temperature, especially from April to June. Moreover, when the ice albedo is no more than 0.5 , the difference among different tests is small. As the albedo increases, the difference in simulated surface temperature increases rapidly. This means that 

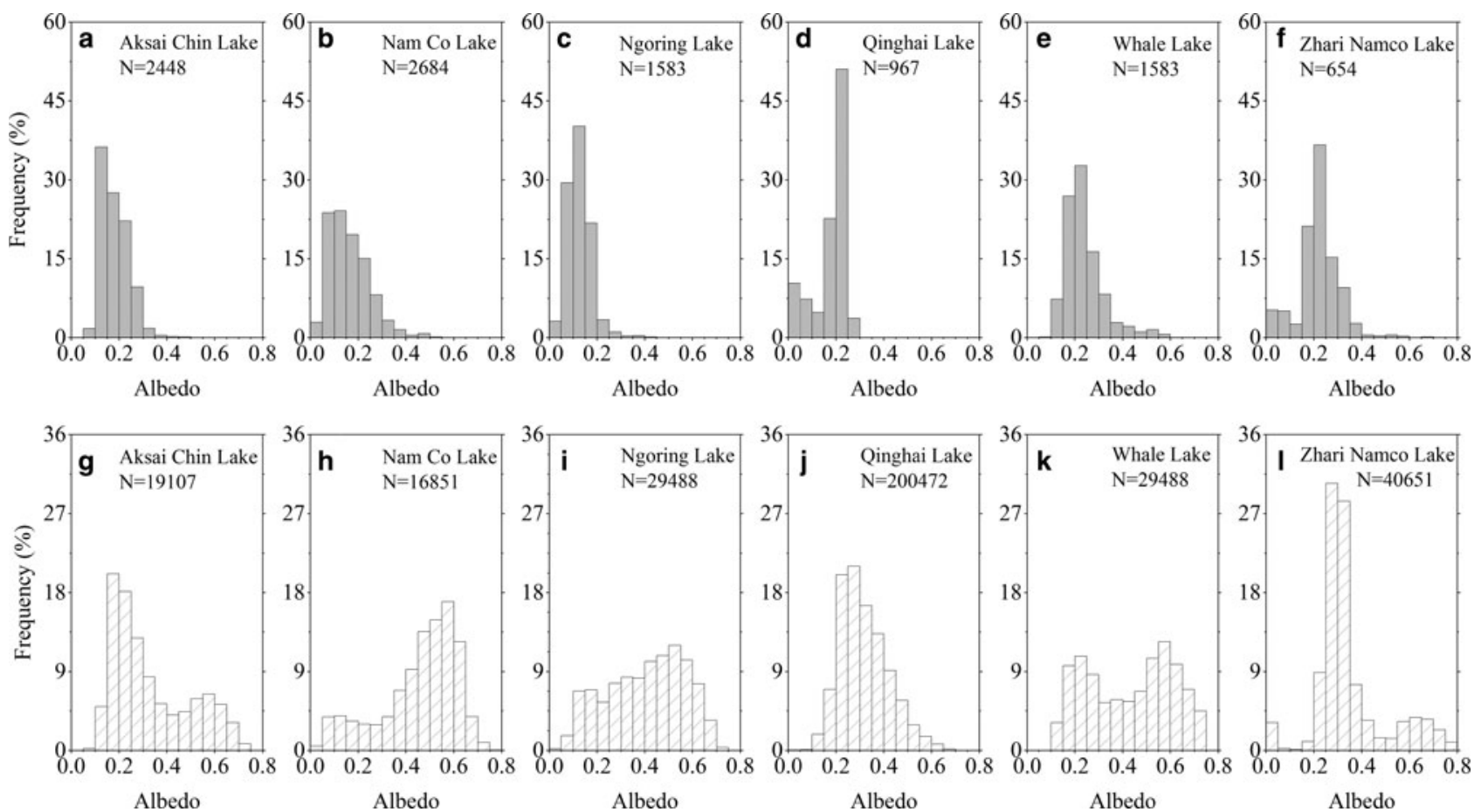

Fig. 10. The distributions of the surface albedos under snow-free (a-f) and all ( $g-l$ ) conditions for six typical TP lakes during the completely frozen period. $N$ is the number of the available sample. Aksai Chin Lake $\left(35.21^{\circ} \mathrm{N}, 79.85^{\circ} \mathrm{E}, 4849 \mathrm{~m}\right.$ a.m.s.l.) is located in the western TP, Nam Co Lake $\left(30.72^{\circ} \mathrm{N}, 90.64^{\circ} \mathrm{E}, 4729 \mathrm{~m}\right.$ a.m.s.I.) and Zhari Namco Lake $\left(30.94^{\circ} \mathrm{N}, 89.45^{\circ} \mathrm{E}, 4617 \mathrm{~m}\right.$ a.m.s.I.) are located in the south-central TP, Whale Lake $\left(36.34^{\circ} \mathrm{N}, 85.61^{\circ} \mathrm{E}, 4718 \mathrm{~m}\right.$ a.m.s. I.) is located in the northwestward TP, and Qinghai Lake $\left(36.93^{\circ} \mathrm{N}, 100.16^{\circ} \mathrm{E}, 3198 \mathrm{~m}\right.$ a.m.s.I.) is located in the northeastward TP.

the ice albedo may have a significant effect on heat exchange and evaporation over the lake, especially in late spring and early summer. Taking example of sensible heat $(H)$ and latent heat (LE) flux from 2012 to 2016 , the averaged $H$ is 29.70, 25.33 and $21.06 \mathrm{~W} \mathrm{~m}^{-2}$ in the experiments with an ice albedo of $0.10,0.40$ and 0.70 , respectively. The $L E$ is 76.63, 72.84 and $67.90 \mathrm{~W} \mathrm{~m}^{-2}$ in three experiments, respectively. When time is set in April, May and June, the decrease in the flux due to high ice albedo will be more obvious $\left(26.68,25.14\right.$ and $18.93 \mathrm{~W} \mathrm{~m}^{-2}$ for $H$; 77.73,
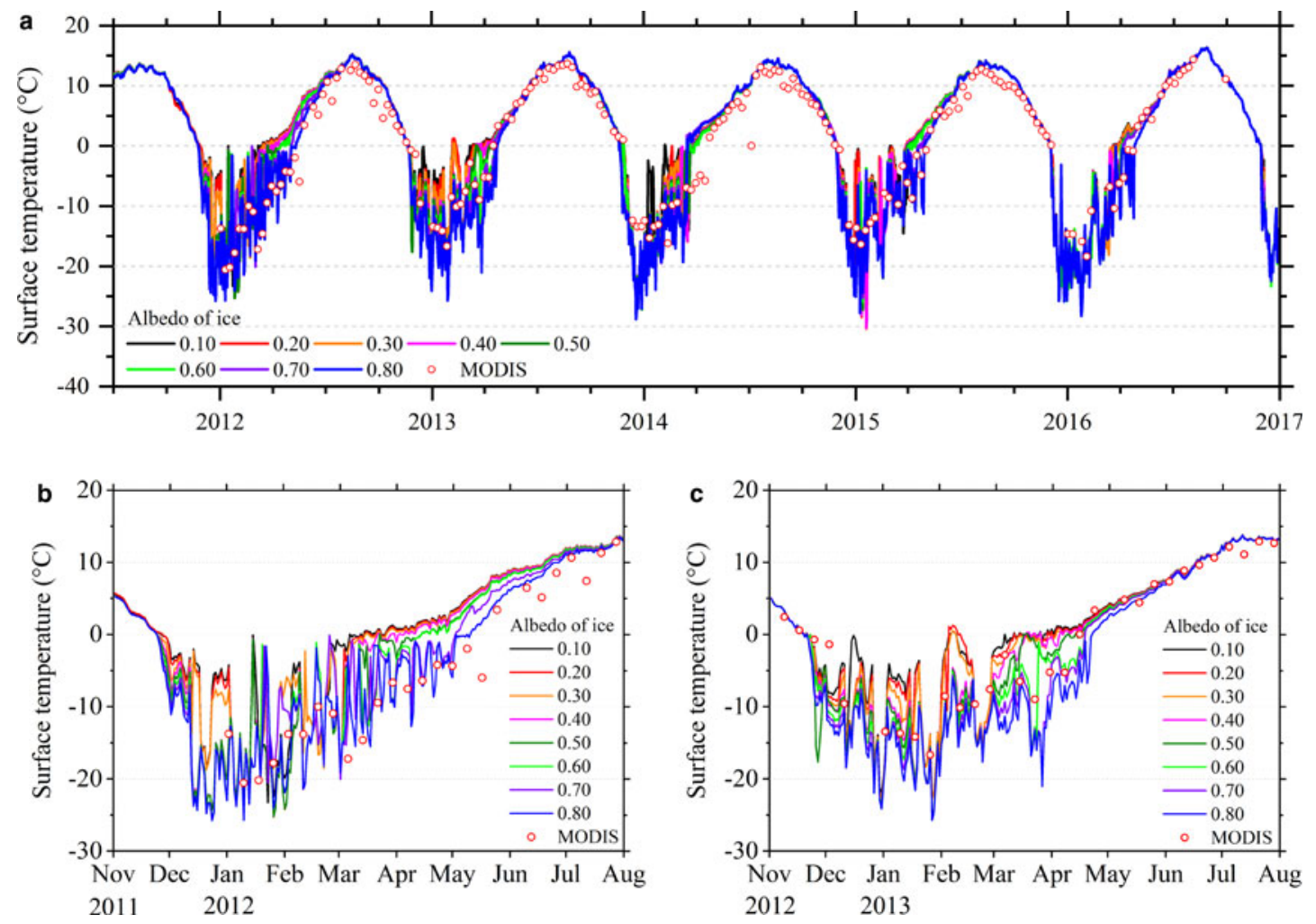

Fig. 11. The daily mean lake surface temperature from MODIS and LAKE 2.0 model using different ice albedos (a) from 20110701 to 20161231, and larger view of segmental (a) ((b) from 20111101 to 20120801 and (c) from 20121101 to 20130801). 


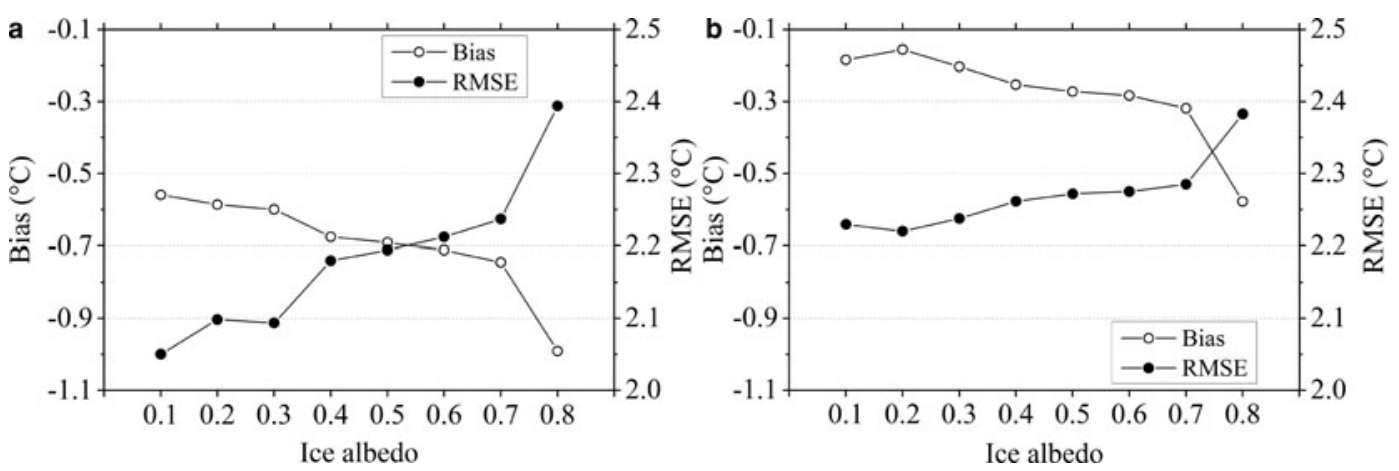

Fig. 12. The bias (simulation-observation) and the root mean square error (RMSE) for lake temperature at $3 \mathrm{~m}$ (a) and $15 \mathrm{~m}$ (b) depths simulated by LAKE 2.0 using different ice albedos, compared with observations from 22 September 2015 to 21 September 2016.

75.43 and $64.41 \mathrm{~W} \mathrm{~m}^{-2}$ for $L E$ ). From November 2011 to June 2012, the surface temperature from high ice-albedo experiment is closest to the observation. In the same time of next year (2012-13), the surface temperature from low ice-albedo experiment is closer to the observation. This appears to be contrary to the previous sections. This phenomenon may be related to the lack of accuracy in the snow simulation during the freezing period. Additionally, previous studies have shown that the MODIS products underestimate the surface temperature (Trigo and others, 2008; Li and others, 2014), which may be expected to result in certain errors.

However, opposed to the surface temperature, the difference in water temperature between simulation and observation (22 September 2015-21 September 2016) shows an opposite trend (Fig. 12). Although the simulated water temperature is underestimated systematically (bias $<0$ ), the bias and the root mean square error (RMSE) all decrease with the decrease of the ice surface albedo. In the shallow layer ( $3 \mathrm{~m}$ depth), the bias and RMSE are the smallest (0.56 and $2.05^{\circ} \mathrm{C}$ ) when the ice albedo is 0.10 . In the deep layer (15 $\mathrm{m}$ depth), the corresponding ice albedo is 0.20 , with $0.16^{\circ} \mathrm{C}$ of bias and $2.22^{\circ} \mathrm{C}$ of RMSE. This means that, for Ngoring Lake, the low ice albedo is more appropriate for the lake temperature simulation.

\section{CONCLUSION}

Based on the field experiment data in Ngoring Lake, we found that the diurnal peak of the ice albedo can reach $\sim 0.30$ after sunrise and before sunset and decreases to $0.08-0.09$ at noon. The ice albedos of $72.21 \%$ of the observed samples are $<0.12$, and $93.38 \%$ of the samples show ice albedos below 0.16 . The relatively clean blue ice (0.6 $\mathrm{m}$ thickness) has an albedo of only 0.075 , which is significantly lower than that reported by previous studies. The lake ice albedo is only 0.212 when covered with snow patches. Overall, the MOD10A1 products have the best agreement with observations, followed by the MYD10A1. The MCD43A3 products are consistently higher than observations and have a few periodicity variations. Due to the errors of the snow flags in MCD43A2 and the inconsistent time windows between MCD43A3 and MCD43A2, the albedo of the lake ice covered with snow is even less than that of snow-free ice at certain times. Apart from the influence of the solar zenith angle, there is no significant correlation between the observed ice albedo and the surface temperature. This conclusion is clearly different from the result derived from temperature-dependent albedo parameterizations. The albedo from CLM4.5 for the near-infrared radiation is the closest to that observed, and the largest deviation is seen in the WRF-FLake model. None of the listed albedo parameterizations can satisfactorily reproduce the observed relationship between the ice albedo and the surface temperature in Ngoring Lake.

\section{ACKNOWLEDGEMENTS}

This research was supported by the National Natural Science Foundation of China (No. 41605011, 91637107, 91537104, 41775016), Sino-German Research Project (GZ1259), the Science and Technology Service Network Initiative of CAREERI, CAS (651671001), and the Foundation for Excellent Youth Scholars of NIEER, CAS (Y651K51001). We thank LAADS for providing the MODIS albedo product data used in this study (https://ladsweb.modaps.eosdis.nasa. gov/). We thank Georgiy Kirillin for his valuable assistance in the water temperature observation in Ngoring Lake and anonymous reviewers for the constructive comments on the paper. Observation data of the IOS and MOP can be freely shared, contact the corresponding author for access to the data.

\section{REFERENCES}

Austin JA and Colman SM (2007) Lake Superior summer water temperatures are increasing more rapidly than regional air temperatures: a positive ice-albedo feedback. Geophys. Res. Lett., 34(6) (doi: 10.1029/2006gl029021)

Biermann T and others (2014) Turbulent flux observations and modelling over a shallow lake and a wet grassland in the Nam Co basin, Tibetan Plateau. Theor. Appl. Climatol., 116(1-2), 301-316

Bolsenga SJ (1969) Total albedo of Great Lakes ice. Water Resour. Res., 5(5), 1132-1133

Bolsenga SJ (1977) Preliminary observations on the daily variation of ice albedo. J. Glaciol., 18, 517-521

Bolsenga SJ (1983) Spectral reflectances of snow and fresh water ice from 340 through $1100 \mathrm{~nm}$. J. Glaciol., 29(102), 296-305

Brock BW, Willis IC and Sharp MJ (2000) Measurement and parameterization of albedo variations at Haut Glacier $d^{\prime}$ Arolla, Switzerland. J. Glaciol., 46(155), 675-688

Efremova TV and Pal'shin NI (2011) Ice phenomena terms on the water bodies of Northwestern Russia. Russ. Meteorol. Hydrol., 36(8), 559-565

Gardner AS and Sharp MJ (2010) A review of snow and ice albedo and the development of a new physically based broadband 
albedo parameterization. J. Geophys. Res., 115(F1) (doi: 10.1029/2009jf001444)

Guo ZM, Wang NL, Jiang X, Mao RJ and Wu HB (2013) Research progress on snow and ice albedo measurement, retrieval and application. Remote Sens. Technol. Appl., 28(4), 194-201, In Chinese with English abstract

Hall A and Qu X (2006) Using the current seasonal cycle to constrain snow albedo feedback in future climate change. Geophys. Res. Lett., 33(3), 155-170

Hall DK and Riggs GA (2007) Accuracy assessment of the MODIS snow products. Hydrol. Process., 21(12), 1534-1547

Hampton SE and 5 others (2008) Sixty years of environmental change in the world's largest freshwater lake - Lake Baikal, Siberia. Global Change Biol., 14(8), 1947-1958

Heron R and Woo M (1994) Decay of a high Arctic lake-ice cover: observations and modeling. J. Glaciol., 40(135), 283-292

Hipsey MR, Bruce LC and Hamilton DP (2014) GLM - General Lake Model: model overview and user information. Version, 2. University of Western Perth, Perth, pp. 1-42.

Huang W and 5 others (2016) Ice processes and surface ablation in a shallow thermokarst lake in the central Qinghai-Tibetan Plateau. Ann. Glaciol., 57(71), 20-28

Hudson SR, Granskog MA, Karlsen TI and Fossan K (2012) An integrated platform for observing the radiation budget of sea ice at different spatial scales. Cold Reg. Sci. Technol., 82, 14-20

Ingram WJ, Wilson CA and Mitchell JFB (1989) Modeling climate change: an assessment of sea ice and surface albedo feedbacks. J. Geophys. Res., 94(D6), 8609-8622

Kirillin G, Wen L and Shatwell T (2017) Seasonal thermal regime and climatic trends in lakes of the Tibetan highlands. Hydrol. Earth Syst. Sci., 21(4), 1895-1909

Lang J, Lyu S, Li Z, Ma Y and Su D (2018) An investigation of ice surface albedo and its influence on the high altitude lakes of the Tibetan Plateau. Remote Sens., 10(2), 218

$\mathrm{Li} \mathrm{H}$ and others (2014) Evaluation of the VIIRS and MODIS LST products in an arid area of Northwest China. Remote Sens. Environ., 142(25), 111-121

Li X and others (2013) Heihe Watershed Allied Telemetry Experimental Research (HiWATER): scientific objectives and experimental design. Bull. Am. Meteorol. Soc., 94(8), 1145-1160

$\mathrm{Li} Z$ and 5 others (2015) Long-term energy flux and radiation balance observations over Lake Ngoring, Tibetan Plateau. Atmos. Res., 155, 13-25

Liu S and 5 others (2016) Upscaling evapotranspiration measurements from multi-site to the satellite pixel scale over heterogeneous land surfaces. Agric. For. Meteorol., 230, 97-113

Mallard MS, Nolte CG, Bullock OR, Spero TL and Gula J (2014) Using a coupled lake model with WRF for dynamical downscaling. J. Geophys. Res., 119(12), 7193-7208

Mironov D and Ritter B (2004) A new sea ice model for GME. Deutscher Wetterdienst, Offenbach am Main, Germany, p. 12

Mironov D and 5 others (2010) Implementation of the lake parameterisation scheme FLake into the numerical weather prediction model COSMO. Boreal Environ. Res., 15(2), 218-230

Mullen PC and Warren SG (1988) Theory of the optical properties of lake ice. J. Geophys. Res., 93(D7), 8403-8414

Nima C and Zhuo G (2012) Preliminary research of attenuation of radiation in the Lake Namtso. J. Tibet Univ., 27(1), 11-14, In Chinese with English abstract

Oleson K and 5 others (2013) Technical Description of version 4.5 of the Community Land Model (CLM). NCAR. National Center for Atmospheric Research (NCAR), Boulder, Colorado, pp. 205-206

O'Reilly CM and others (2015) Rapid and highly variable warming of lake surface waters around the globe. Geophys. Res. Lett., 42(24), 10733-10781 (doi: 10.1002/2015GL066235)
Pärn O, Jaatinen E, Erm A, Leppäranta M and Lei R (2011) Field investigations of apparent optical properties of ice cover in Finnish and Estonian lakes in winter 2009. Est. J. Earth Sci., 60(1), 50

Pirazzini R (2009) Challenges in snow and ice albedo parameterizations. Geophysica, 45(1-2), 41-62

Pirazzini R, Vihma T, Granskog MA and Cheng B (2006) Surface albedo measurements over sea ice in the Baltic Sea during the spring snowmelt period. Ann. Glaciol., 44(1), 7-14

Post DF and others (2000) Predicting soil albedo from soil color and spectral reflectance data. Soil Sci. Soc. Am. J., 64(3), 1027-1034

Roesch A, Gilgen H, Wild M and Ohmura A (1999) Assessment of GCM simulated snow albedo using direct observations. Clim. Dyn., 15(6), 405-418

Roesch A, Wild M, Pinker R and Ohmura A (2002) Comparison of spectral surface albedos and their impact on the general circulation model simulated surface climate. J. Geopys. Res., 107(D14) (doi: 10.1029/2001JD000809)

Ross B and Walsh JE (1987) A comparison of simulated and observed fluctuations in summertime Arctic surface albedo. J. Geophys Res., 92(C12), 13115-131125

Rouse WR and 5 others (2003) Interannual and seasonal variability of the surface energy balance and temperature of central Great Slave Lake. J. Hydrometeor., 4(4), 720-730

Semmler T, Cheng B, Yang Y and Rontu L (2012) Snow and ice on Bear Lake (Alaska) - sensitivity experiments with two lake ice models. Tellus A, 64 (doi: 10.3402/tellusa.v3464i3400.17339)

Stepanenko VM and Lykossov VN (2005) Numerical modeling of heat and moisture transfer processes in a system lake-soil. Russ. J. Meteorol. Hydrol., 3, 95-104

Stepanenko V and 5 others (2016) LAKE 2.0: a model for temperature, methane, carbon dioxide and oxygen dynamics in lakes. Geosci. Model Dev., 9(5), 1977-2006

Stepanenko VM, Machul'skaya EE, Glagolev MV and Lykossov VN (2011) Numerical modeling of methane emissions from lakes in the permafrost zone. Izvestiya, Atmos. Oceanic Phys., 47(2), 252-264

Svacina NA, Duguay CR and King JML (2014) Modelled and satellite-derived surface albedo of lake ice - part II: evaluation of MODIS albedo products. Hydrol. Process., 28(16), 4562-4572

Trigo I, Monteiro I, Olesen F and Kabsch E (2008) An assessment of remotely sensed land surface temperature. J. Geophys. Res., 113 (D17108) (doi: 10.1029/2008JD010035)

Wang B, Ma Y, Ma W and Su Z (2017) Physical controls on halfhourly, daily, and monthly turbulent flux and energy budget over a high-altitude small lake on the Tibetan Plateau. J. Geophys. Res., 122(4), 2289-2303

Warren SG (1982) Optical properties of snow. Rev. Geophys., 20(1), 67-89

Wilber AC, Kratz DP and Gupta SK, (1999) Surface emissivity maps for use in satellite retrievals of longwave radiation. p. 35pp

Yang K and 5 others (2013) A multiscale soil moisture and freezethaw monitoring network on the third pole. Bull. Am. Meteorol. Soc., 94(12), 1907-1916

Zdorovennova G, Zdorovennov R, Palshin N and Terzhevik A (2013) Optical properties of the ice cover on Vendyurskoe lake, Russian Karelia (1995-2012). Ann. Glaciol., 54(62), 121-124

Zhang G, Yao T, Xie H, Zhang K and Zhu F (2014) Lakes' state and abundance across the Tibetan Plateau. Chin. Sci. Bull., 59(24), 3010-3021

Zhang G and others (2017) Extensive and drastically different alpine lake changes on Asia's high plateaus during the past four decades. Geophys. Res. Lett., 44(1), 252-260 (doi: 10.1002/ 2016GL072033) 